\title{
Intracranial hemorrhage in adult patients with hematological malignancies
}

Chien-Yuan Chen ${ }^{1 *}$, Chan-Hwei Tai ${ }^{2}$, Aristine Cheng ${ }^{1}$, Hung-Chang Wu ${ }^{3}$, Woei Tsay ${ }^{1}$, Jia-Hau Liu ${ }^{1,4}$, Pey-Ying Chen ${ }^{5}$, Shang-Yi Huang ${ }^{1}$, Ming Yao ${ }^{1}$, Jih-Luh Tang ${ }^{1,4}$ and Hwei-Fang Tien ${ }^{1 *}$

\begin{abstract}
Background: Clinical characteristics and outcomes of intracranial hemorrhage (ICH) among adult patients with various hematological malignancies are limited.

Methods: A total of 2,574 adult patients diagnosed with hematological malignancies admitted to a single university hospital were enrolled into this study between 2001 and 2010. The clinical characteristics, image reports and outcomes were retrospectively analyzed.

Results: A total of 72 patients (48 men and 24 women) with a median age of 56 (range 18 to 86 ) had an ICH. The overall ICH incidence was $2.8 \%$ among adult patients with hematological malignancies. The incidence of ICH was higher in acute myeloid leukemia (AML) patients than in patients with other hematological malignancies (6.3\% vs $1.1 \%, P=0.001)$. ICH was more common among patients with central nervous system (CNS) involvement of lymphoma than among patients with CNS involved acute leukemia $(P<0.001)$. Sites of ICH occurrence included the cerebral cortex (60 patients, 83\%), basal ganglia (13 patients, 18\%), cerebellum (10 patients, 14\%), and brainstem (5 patients, 7\%). A total of 33 patients (46\%) had multifocal hemorrhages. In all, 56 patients (77\%) had intraparenchymal hemorrhage, 22 patients (31\%) had subdural hemorrhage, 15 patients (21\%) had subarachnoid hemorrhage $(\mathrm{SAH})$, and 3 patients (4\%) had epidural hemorrhage. A total of 22 patients had 2 or more types of ICH. In all, 46 (64\%) patients died of ICH within 30 days of diagnosis, irrespective of the type of hematological malignancy. Multivariate analysis revealed three independent prognostic factors: prolonged prothrombin time $(P=0.008)$, SAH $(P=0.021)$, and multifocal cerebral hemorrhage $(P=0.026)$.
\end{abstract}

Conclusions: The incidence of $\mathrm{ICH}$ in patients with $\mathrm{AML}$ is higher than patients with other hematological malignancies. But in those with intracranial malignant disease, patients with CNS involved lymphoma were more prone to ICH than patients with CNS involved acute leukemia. Mortality was similar regardless of the type of hematological malignancy. Neuroimaging studies of the location and type of $\mathrm{ICH}$ could assist with prognosis prediction for patients with hematological malignancies.

Keywords: central nervous system (CNS) involvement, cerebral hemorrhage, hematological malignancy, prognosis, neuroimage

\section{Background}

In adult patients with hematological malignancies, infection is the most common complication. Intracranial hemorrhage (ICH) is the second most common complication, and is associated with high morbidity and mortality [1-4]. Several comprehensive reviews have highlighted the

\footnotetext{
* Correspondence: chienyuanchen@ntu.edu.tw; tienhf@ntu.edu.tw 'Department of Internal Medicine, National Taiwan University Hospital, Taipei, Taiwan Full list of author information is available at the end of the article
}

following risk factors for $\mathrm{ICH}$ in cancer patients: hypertension, vessel wall abnormality, invasion or compression of vessels from a tumor in or adjacent to the brain, low platelet count or platelet dysfunction, coagulation factor deficiency, disseminated intravascular coagulation (DIC), sepsis, and hyperleukocytosis [1,5-8]. Hematological malignancies comprise a diverse group of neoplasms, and may directly or indirectly lead to neurological complications and $\mathrm{ICH}[9,10]$. In recent decades, prophylactic platelet transfusions to maintain the platelet count at a
C Biomed Central 
safe threshold have decreased the risk of hemorrhagic complication [11,12]. However, ICH is still a frequent complication in patients with hematological malignancies, and many questions remain unanswered with regard to the clinical management of $\mathrm{ICH}$ in patients with hematological malignancies.

Patients with lymphoid malignancy more frequently experience central nervous system (CNS) involvement than do patients with myeloid leukemia [13,14]. ICH could be the initial presentation in patients with hematological malignancies $[15,16]$. The relationship of ICH and CNS involvement is still underinvestigated. Evidence on the clinical manifestations in $\mathrm{ICH}$ among the various hematological malignancies is relatively limited. To clarify the clinical manifestations and prognosis of $\mathrm{ICH}$ among patients with hematological malignancies, we retrospectively reviewed the medical records of patients admitted to the National Taiwan University Hospital between 2001 and 2010, and analyzed the data.

\section{Methods}

\section{Patients and hospital setting}

National Taiwan University Hospital (NTUH) is a 2,600bed teaching hospital in northern Taiwan that provides both primary and tertiary care. We retrospectively analyzed the demographic features, hematological disease status, underlying medical diseases, laboratory and microbiological data, and outcomes of all adult patients with hematological malignancies from January 2001 to December 2010 at NTUH. The laboratory data was collected promptly after onset of $\mathrm{ICH}$. We also assessed the overall 30-day mortality of these patients. This research conformed to the Helsinki Declaration and local legislation, and was approved by the National Taiwan University Hospital Research Ethics Committee.

\section{Chemotherapy in patients with hematological malignancies}

Induction chemotherapy consisted of cytarabine and anthracycline for patients with acute myeloid leukemia (AML). Consolidation chemotherapy consisted of highdose cytarabine-based regimens. Patients with acute promyelocytic leukemia (APL) were treated with all-trans retinoic acid (ATRA) and combined anthracycline-based chemotherapy. Patients diagnosed with acute lymphoblastic leukemia received a Cancer and Leukemia Group B 8811 (CALGB8811) [17] or Group for Research on Adult Acute Lymphoblastic Leukemia 2003 (GRAALL 2003) chemotherapy protocol [18]. Patients diagnosed with lymphoma generally received a chemotherapy regimen consisting of CHOP (cyclophosphamide, hydroxydaunorubicin (Adriamycin), vincristine (Oncovin), and prednisolone) with or without rituximab. Lymphoma patients with CNS involvement received high-dose methotrexate-based chemotherapy [19]. Patients with myeloma were treated with thalidomide, or VAD [20] (vincristine, Adriamycin, and dexamethasone) or DCEP [21] (dexamethasone, cyclophosphamide, etoposide, and cisplatin (Platin)) chemotherapy, according to the clinical decision.

\section{Hyperviscosity}

Hyperviscosity syndrome is defined by the presence of elevated serum immunoglobulins in conjunction with clinical constitutional symptoms, bleeding, ocular, neurological, and cardiovascular manifestations [22].

\section{Policy of platelet transfusion in patients with hematological malignancy}

The platelet counts were checked three times per week during chemotherapy in patients with hematological malignancies until the neutrophil counts recovered. The platelet counts were checked once to three times per week after neutrophil counts recovered according to clinical judgment. The complete blood counts were checked once per day in patients with freshly diagnosed acute promyelocytic leukemia until complete remission. Prophylactic platelet transfusions were used to maintain the platelet level above 20,000 cells/ $\mu \mathrm{l}$ in patients receiving chemotherapy. Among patients with acute promyelocytic leukemia, active bleeding, and sepsis, the platelet counts were maintained above 50,000 cells/ $\mu$ l or more according to clinical judgment.

\section{Diagnosis of $\mathrm{ICH}$ and inclusion/exclusion criteria}

Each patient's ICH diagnosis was determined from both clinical and neuroimaging findings. Either computed tomogram or magnetic resonance imaging was required to confirm the clinical diagnosis of $\mathrm{ICH}$. Patients for whom $\mathrm{ICH}$ was suspected but unproven were excluded. Patients with ischemic stroke and subsequent hemorrhagic transformation were also excluded. Types and locations of intracranial hemorrhage were determined from radiology reports. According to the neuroimaging results, hemorrhages were classified into four types, namely intraparenchymal hemorrhage (IPH), subarachnoid hemorrhage $(\mathrm{SAH})$, subdural hemorrhage $(\mathrm{SDH})$, and epidural hemorrhage (EDH) [5].

\section{End points and overall survival}

The starting point was the date of diagnosis of $\mathrm{ICH}$. The primary end point was $\mathrm{ICH}$-related death within 30 days. Survival time was the time interval from diagnosis of $\mathrm{ICH}$ to events such as death from any cause.

\section{Statistical analysis}

For continuous variables, data are reported as the median with the range shown in brackets. For nominal 
variables, data are reported as the number of patients, unless specified otherwise. Survival curves were plotted using Kaplan-Meier analysis, and differences between curves were analyzed by log rank. All factors in the univariate analyses were also enrolled in multivariate analysis using Cox proportional-hazard testing. All statistical analyses were performed using SPSS 18.0 for Windows (SPSS, Chicago, IL, USA), and $P$ values of less than 0.05 were considered statistically significant.

\section{Results}

\section{ICH among patients of hematological malignancies}

A total of 2,574 adult patients with hematological malignancies were admitted to National Taiwan University Hospital between 2001 and 2010. During that period, 72 episodes of ICH developed in 72 of these patients (48 men and 24 women); the median age of the ICH group was 56 years (range: 18 to 86 years). The ICH patients included 52 (6.3\%) of 818 patients who had AML, 5 (2.0\%) of 250 patients with acute lymphoblastic leukemia (ALL), 7 (0.7\%) of 1,001 patients with lymphoma, and 8 (2.7\%) of 291 patients with myeloma. Of the 214 patients who had chronic myeloid leukemia or chronic lymphoid leukemia, none developed ICH. Our results indicated an overall ICH incidence of $2.8 \%$ among adult patients with hematological malignancies. Patients with AML displayed a particularly high incidence of ICH compared with patients with other hematological malignancies $(6.3 \%$ vs $1.1 \% ; P=0.001$; odds ratio (OR): $5.89 ; 95 \%$ confidence interval (CI): 3.49 to 9.93). Except acute promyelocytic leukemia, the incidence of $\mathrm{ICH}$ is no different among AML French-American-British (FAB) subtypes. The clinical characteristics of ICH in patients with hematological malignancies are shown in Table 1.

Among the 72 patients with $\mathrm{ICH}, 46$ (64\%) had thrombocytopenia (platelets less than 20,000 cells/ $\mu \mathrm{l}), 34$ (47\%) had sepsis, and 15 (21\%) had prolongation of prothrombin time. Thrombocytopenia, sepsis and prolongation of prothrombin time are proposed as the potential major causes of ICH. In all, 28 patients had brain magnetic resonance angiography to survey the vascular abnormality during ICH. Neither aneurysm nor arteriovenous malformation was detected in this study. The clinical characteristics, including age, sex, hypertension, sepsis, remission status, and allogeneic stem cell transplantation were not statistically different among ICH patients with various hematological malignancies.

$\mathrm{ICH}$ patients who were diagnosed with lymphoma and myeloma had higher rates of CNS involvement than patients with other hematological malignancies $(P<0.001)$. Two of five lymphoma patients with CNS involvement had been diagnosed with primary CNS lymphoma. One patient with diffuse large $\mathrm{B}$ cell lymphoma and one patient with primary CNS lymphoma developed ICH before the start of systemic chemotherapy. The other three lymphoma patients who developed ICH during lymphoma relapsed. One myeloma patient showed immature plasma cells in the cerebrospinal fluid, but no direct tumor involvement with the CNS. None of the eight myeloma patients had hyperviscosity syndrome during ICH. L-Asparaginase was used as a combined chemotherapy protocol in two ICH patients with ALL, but no statistically significant difference was found for other clinical manifestations among ICH patients.

Thrombocytopenia and prolongation of prothrombin time have been recognized as risk factors for CNS hemorrhage in patients with hematological malignancy $[2,4]$. In this study, we found patients with prolongation of prothrombin time had a trend towards developing SAH and significantly higher risk of death $(P=0.008)$. However, the platelet count and prothrombin time were not statistically significantly different among ICH patients with various hematological malignancies.

\section{Locations and types of ICH}

The locations and types of $\mathrm{ICH}$ in patients with different types of hematological malignancies are shown in Table 1. ICH locations included the cerebral cortex (60 patients, $83 \%$ ), basal ganglia (13 patients, $18 \%$ ), cerebellum (10 patients, 14\%), and brainstem (5 patients, $7 \%)$. A total of 33 patients (46\%) had multifocal hemorrhage. Neuroimaging studies revealed that 56 patients (77\%) had IPH, 22 patients (31\%) had SDH, 15 patients (21\%) had SAH, and 3 patients (4\%) had EDH. In all, 22 patients had 2 or more types of $\mathrm{ICH}$, including 11 patients with IPH and SAH, 6 patients with IPH and SDH, 1 patient with IPH and EDH, 1 patient with SDH and $\mathrm{SAH}, 1$ patient with SDH and EDH, and 2 patients with IPH, SAH, and SDH. Hemorrhage ruptured into the ventricles (IVH) in 22 patients (31\%). EDH occurred most frequently in patients with myeloma, and neuroimaging showed no definite focal lesion in the cranial vault.

The correlations between clinical characteristics and types of ICH are shown in Table 2. Younger age was associated with risk of IPH $(P=0.009)$, and more advanced age was associated with SDH $(P=0.002)$. Hyperleukocytosis (white blood cell count more than $100,000$ cells $/ \mu \mathrm{l})$ showed a trend of being associated with IPH $(P=0.056)$. There were 12 patients with hyperleukocytosis at the time of ICH. All 12 patients had IPH (12/ $12,100 \%)$. One patient had both IPH and SDH, but no patients had SAH and EDH.

\section{Correlated clinical manifestation and outcome in patients with ICH}

In total, 25 patients (35\%) died within $72 \mathrm{~h}$ of the onset of $\mathrm{ICH}$, and 46 patients (64\%) died within 30 days of 
Table 1 Clinical characteristics of intracranial hemorrhage among patients of different types of hematological malignancies

\begin{tabular}{|c|c|c|c|c|c|c|}
\hline \multirow[b]{2}{*}{ Subtype } & \multicolumn{6}{|c|}{ Number of patients } \\
\hline & $\overline{A M L}(n=43)$ & APL $(n=9)$ & ALL $(n=5)$ & Lymphoma $(n=7)$ & Myeloma $(n=8)$ & $P$ value \\
\hline Age: & & & & & & 0.094 \\
\hline$\geq 60$ years & 19 & 2 & 1 & 6 & 4 & \\
\hline$<60$ years & 24 & 7 & 4 & 1 & 4 & \\
\hline Gender: & & & & & & 0.461 \\
\hline Male & 32 & 5 & 2 & 4 & 5 & \\
\hline Female & 11 & 4 & 3 & 3 & 3 & \\
\hline Underlying hypertension: & & & & & & 0.428 \\
\hline Yes & 12 & 3 & 0 & 3 & 1 & \\
\hline No & 31 & 6 & 5 & 4 & 7 & \\
\hline Diabetes mellitus: & & & & & & 0.274 \\
\hline Yes & 3 & 1 & 0 & 2 & 0 & \\
\hline No & 40 & 8 & 5 & 5 & 8 & \\
\hline Sepsis: & & & & & & 0.096 \\
\hline Yes & 16 & 5 & 5 & 4 & 4 & \\
\hline No & 27 & 4 & 0 & 3 & 4 & \\
\hline Post HSCT: & & & & & & 0.347 \\
\hline Yes & 8 & 0 & 0 & 0 & 1 & \\
\hline No & 35 & 9 & 5 & 7 & 7 & \\
\hline Disease status: & & & & & & 0.409 \\
\hline Remission & 6 & 2 & 0 & 0 & 0 & \\
\hline Active & 37 & 7 & 5 & 7 & 8 & \\
\hline CNS involvement: & & & & & & $<0.001$ \\
\hline Yes & 0 & 0 & 0 & 5 & 1 & \\
\hline No & 43 & 9 & 5 & 2 & 7 & \\
\hline Leukocyte count: & & & & & & 0.642 \\
\hline$\geq 100,000$ cells $/ \mu \mathrm{l}$ & 9 & 2 & 0 & 1 & 0 & \\
\hline$<100,000$ cells $/ \mu l$ & 34 & 7 & 5 & 6 & 8 & \\
\hline Platelet count: & & & & & & 0.560 \\
\hline$\geq 20,000$ cells $/ \mu l$ & 27 & 6 & 3 & 6 & 4 & \\
\hline$<20,000$ cells $/ \mu l$ & 16 & 3 & 2 & 1 & 4 & \\
\hline Prothrombin time: & & & & & & 0.493 \\
\hline INR $\geq 1.5$ & 10 & 2 & 1 & 1 & 1 & \\
\hline INR $<1.5$ & 32 & 7 & 4 & 6 & 7 & \\
\hline \multicolumn{7}{|l|}{ Location: } \\
\hline Cerebral cortex & 37 & 7 & 5 & 4 & 5 & 0.326 \\
\hline Basal ganglia & 9 & 1 & 1 & 1 & 1 & 0.941 \\
\hline Brainstem & 4 & 0 & 0 & 1 & 0 & 0.628 \\
\hline Cerebellum & 4 & 2 & 0 & 1 & 3 & 0.213 \\
\hline Multiple & 20 & 5 & 0 & 3 & 5 & 0.240 \\
\hline \multicolumn{7}{|l|}{ Type: } \\
\hline Intraparenchymal hemorrhage & 35 & 7 & 5 & 4 & 5 & 0.336 \\
\hline Subarachnoid hemorrhage & 8 & 2 & 2 & 0 & 3 & 0.349 \\
\hline Subdural hemorrhage & 11 & 2 & 1 & 4 & 4 & 0.307 \\
\hline Epidural hemorrhage & 1 & 0 & 0 & 0 & 2 & 0.041 \\
\hline Intraventricular hemorrhage & 10 & 4 & 1 & 3 & 2 & 0.618 \\
\hline
\end{tabular}

$\mathrm{ALL}$ = acute lymphoblastic leukemia; $\mathrm{AML}=$ acute myeloid leukemia; $\mathrm{APL}=$ acute promyelocytic leukemia; $\mathrm{CNS}=$ central nervous system; $\mathrm{HSCT}=$ hematopoietic stem cell transplantation; INR = international normalized ratio. 
Table 2 Clinical characteristics and types of intracranial hemorrhage

\begin{tabular}{|c|c|c|c|c|c|c|}
\hline & $\mathrm{IPH}(\mathrm{n}=56)$ & $P$ value & SDH $(n=22)$ & $P$ value & SAH $(n=15)$ & $P$ value \\
\hline Gender: & & 0.137 & & 0.180 & & 0.552 \\
\hline Male & 40 & & 12 & & 9 & \\
\hline Female & 16 & & 10 & & 6 & \\
\hline Age: & & 0.009 & & 0.002 & & $>0.999$ \\
\hline$\geq 60$ years & 20 & & 16 & & 7 & \\
\hline$<60$ years & 36 & & 6 & & 8 & \\
\hline Underlying hypertension: & & 0.335 & & 0.565 & & 0.324 \\
\hline Yes & 13 & & 7 & & 2 & \\
\hline No & 43 & & 15 & & 13 & \\
\hline Sepsis: & & 0.168 & & 0.306 & & 0.384 \\
\hline Yes & 29 & & 8 & & 9 & \\
\hline No & 27 & & 14 & & 6 & \\
\hline Remission status: & & $>0.999$ & & 0.421 & & 0.669 \\
\hline Yes & 6 & & 1 & & 2 & \\
\hline No & 50 & & 21 & & 13 & \\
\hline CNS involvement: & & 0.609 & & 0.361 & & $>0.999$ \\
\hline Yes & 4 & & 3 & & 1 & \\
\hline No & 52 & & 19 & & 14 & \\
\hline Leukocyte count: & & 0.056 & & 0.090 & & 0.060 \\
\hline$\geq 100,000$ cells $/ \mu \mathrm{l}$ & 12 & & 1 & & 0 & \\
\hline$<100,000$ cells $/ \mu \mathrm{l}$ & 44 & & 21 & & 15 & \\
\hline Platelet count: & & $>0.999$ & & 0.603 & & 0.376 \\
\hline$\geq 20,000$ cells $/ \mu l$ & 36 & & 9 & & 7 & \\
\hline$<20,000$ cells $/ \mu \mathrm{l}$ & 20 & & 13 & & 8 & \\
\hline Prothrombin time: & & 0.495 & & 0.127 & & 0.069 \\
\hline INR $\geq 1.5$ & 43 & & 2 & & 6 & \\
\hline INR $<1.5$ & 13 & & 20 & & 9 & \\
\hline
\end{tabular}

CNS = central nervous system; INR = international normalized ratio; IPH = intraparenchymal hemorrhage; SAH = subarachnoid hemorrhage; SDH = subdural hemorrhage.

ICH. Mortality was high among patients with EDH (3/ $3,100 \%)$ and SAH $(14 / 15,93 \%)$, but was relatively lower in patients with SDH $(11 / 22,50 \%)$. Most patients received conservative component therapy only, but 11 patients (15\%) underwent craniotomy and hematoma evacuation (6 patients with IPH, 2 patients with SDH, 2 patients with both IPH and SDH, and 1 patient with SDH and EDH). Seven patients survived for 30 days (four patients with IPH, two patients with SDH, and one patient with both IPH and SDH). Five of seven survivors had long-term survival (more than 1 year) with minimal neurological sequelae. Surgical intervention showed a trend of improved 30-day outcome $(P=0.085)$.

To clarify the clinical manifestations for the 30-day outcome in patients with hematological malignancies, we analyzed clinical prognostic factors as shown in Table 3. Univariate analysis revealed that sepsis $(P=0.05), \mathrm{SAH}$ $(P=0.007)$, multifocal cerebral hemorrhage $(P=0.006)$, and prolonged prothrombin duration $(P=0.013)$ were associated with poor prognosis. The type of hematological malignancy had no effect on the 30-day outcome, nor did allogeneic stem cell transplantation.
All covariates with a $P$ value less than 0.1 were enrolled in the multivariate analysis. Multivariate analysis was conducted using the Cox proportional hazard test, shown in Table 3. Poor outcome of ICH in patients with hematological malignancies was associated with three independent factors, namely prolonged prothrombin duration $(P=$ 0.008; OR 10.5 ; $95 \%$ CI 1.3 to 85.5$)$, SAH $(P=0.021$; OR 10.9 ; $95 \%$ CI 1.3 to 89.9 ), and multifocal cerebral hemorrhage ( $P=0.026$; OR $4.7 ; 95 \%$ CI 1.6 to 14.0$)$. Surgical intervention showed a trend of being associated with improved prognosis in the univariate analysis $(P=0.085)$, but no statistical significance was found for this relationship in the multivariate analysis.

\section{Discussion}

The cause of ICH is very important and holds implications for further therapy. Since no patient received autopsy after $\mathrm{ICH}$, the definite cause of $\mathrm{ICH}$ in patients with hematological malignancies is inconclusive. Among the 72 patients with ICH, 46 (64\%) patients had thrombocytopenia (platelets less than 20,000 cells/ $\mu \mathrm{l}), 34$ (47\%) had sepsis, and 15 (21\%) had prolongation of prothrombin time. Consequently, 
Table 3 Univariate analysis of 30-day outcome of ICH among patients with hematological malignancies.

\begin{tabular}{|c|c|c|c|c|}
\hline & Alive $(n=26)$ & Dead $(n=46)$ & Univariate analysis, $P$ value & $\begin{array}{l}\text { Multivariate analysis, } P \text { value } \\
\text { (odds ratio; } 95 \% \mathrm{Cl} \text { ) }\end{array}$ \\
\hline Gender: & & & 0.604 & \\
\hline Male & 16 & 32 & & \\
\hline Female & 10 & 14 & & \\
\hline Age & & & $>0.999$ & \\
\hline$\geq 60$ years & 12 & 20 & & \\
\hline$<60$ years & 14 & 26 & & \\
\hline Hematological malignancies & & & 0.679 & \\
\hline AML & 14 & 29 & & \\
\hline APL & 5 & 4 & & \\
\hline ALL & 2 & 3 & & \\
\hline Lymphoma & 3 & 4 & & \\
\hline Myeloma & 2 & 6 & & \\
\hline Remission status & & & 0.448 & \\
\hline Yes & 4 & 4 & & \\
\hline No & 22 & 42 & & \\
\hline Post HSCT & & & 0.473 & \\
\hline Yes & 2 & 7 & & \\
\hline No & 24 & 39 & & \\
\hline Underlying hypertension & & & $>0.999$ & \\
\hline Yes & 7 & 12 & & \\
\hline No & 19 & 34 & & \\
\hline Sepsis & & & 0.050 & \\
\hline Yes & 8 & 26 & & \\
\hline No & 18 & 20 & & \\
\hline CNS involvement & & & $>0.999$ & \\
\hline Yes & 2 & 4 & & \\
\hline No & 24 & 42 & & \\
\hline Subarachnoid hemorrhage & & & 0.007 & $0.021(10.9 ; 1.3$ to 88.9$)$ \\
\hline Yes & 1 & 14 & & \\
\hline No & 25 & 32 & & \\
\hline Multifocal hemorrhage & & & 0.006 & $0.026(4.7 ; 1.6$ to 14.0$)$ \\
\hline Yes & 6 & 27 & & \\
\hline No & 20 & 19 & & \\
\hline Surgical intervention & & & 0.085 & \\
\hline Yes & 7 & 4 & & \\
\hline No & 19 & 41 & & \\
\hline Leukocyte count & & & $>0.999$ & \\
\hline$\geq 100,000$ cells $/ \mu \mathrm{l}$ & 4 & 8 & & \\
\hline$<100,000$ cells $/ \mu \mathrm{l}$ & 22 & 38 & & \\
\hline Platelet count & & & 0.802 & \\
\hline$\geq 20,000$ cells $/ \mu \mathrm{l}$ & 16 & 30 & & \\
\hline$<20,000$ cells $/ \mu \mathrm{l}$ & 10 & 16 & & \\
\hline Prolongation of prothrombin time & & & 0.013 & $0.008(10.9 ; 1.3$ to 85.5$)$ \\
\hline INR $\geq 1.5$ & 1 & 14 & & \\
\hline INR $<1.5$ & 24 & 32 & & \\
\hline
\end{tabular}


thrombocytopenia, sepsis and prolongation of prothrombin time are the major predisposing factors for $\mathrm{ICH}$.

The definite causes of $\mathrm{ICH}$ could be further investigated by autopsy study. Occurrence of $\mathrm{ICH}$ in patients with acute leukemia has been reported [3,4]. Case reports of $\mathrm{ICH}$ included patients with primary CNS lymphoma [23-25], intravascular lymphoma [26,27], and myeloma $[28,29]$. However, comparisons of the clinical characteristics and outcome in patients with various hematological malignancies were limited. The current study reveals that patients with AML had a higher incidence of ICH than patients with other hematological malignancies (6.3\% vs $1.1 \% ; P=0.001$ ).

The incidence of ICH is less common in patients with lymphoma and myeloma, among those with intracranial involvement. ICH occurred more frequently in patients with CNS involved lymphoid malignancy relative to those with CNS involved acute leukemia. The pathogenesis of ICH among patients with various hematological malignancies may be different. Leukemias are circulating precursors of lymphoblastic or myeloid neoplasm that involve the bone marrow and peripheral blood. Leukemias often exert an indirect effect on the nervous system, causing thrombocytopenia, coagulation factor deficiency, sepsis, therapyrelated complications, and vessel wall abnormalities [9]. In contrast, for most lymphoma and myeloma patients, the tumor cells do not invade tissues and vessels. As Glass [9] proposed, the tumor cells may exert direct effects as solid tissue tumors on cerebral tissue and blood vessels, resulting in vascular occlusion and end-organ ischemia, which in turn, potentially cause thrombosis and hemorrhagic transformation. In the current study, we considered that $\mathrm{ICH}$ might partly contribute to the direct invasion or intravascular involvement of tumor cells in patients with lymphoma and myeloma, and the definite mechanism of lymphoma and myeloma associated $\mathrm{ICH}$ should be further investigated.

Patients with CNS lymphoma or myeloma involvement should be aware of the increased risk of ICH [23-27]. L-Asparaginase is one of the combined chemotherapy agents frequently used to treat acute lymphoblastic leukemia; it may decrease the plasma antithrombin and fibrinogen levels, potentially inducing bleeding [30]. Hyperviscosity syndrome and direct tumor invasion also have been reported, which could lead to fatal ICH in patients with multiple myelomas [28,29]. L-asparaginase and myeloma associated hyperviscosity syndrome implicate bleeding tendency, however, both factors did not disclose the clinical significance of outcome in $\mathrm{ICH}$ patients with hematological malignancies in the current study

The types and locations of ICH events in patients with hematological malignancies are also rarely reported $[2,5,31]$. A rapid onset of focal neurological deficit with clinical signs of increased intracranial pressure is strongly suggestive of a diagnosis of $\mathrm{ICH}$, but cranial imaging is required to differentiate it from ischemic stroke $[32,33]$. In this study, neuroimaging not only disclosed the types and locations of $\mathrm{ICH}$, but could also predict the outcome of patients with $\mathrm{ICH}$. A neuroimaging study should be performed rapidly after symptoms or signs of neurological deficit in patients with hematological malignancies.

We found most (78\%) ICH events in patients with hematological malignancies tended to be IPH, which was congruent with prior reports $[5,34]$. Subdural hemorrhage is common among older members of the general population [35]. Among our study patients with hematological malignancies, older patients had more SDH than younger patients $(P=0.002)$. Symptoms of SDH have a slower onset than those of $\mathrm{ICH}$, because the lower pressure in veins causes them to bleed more slowly than arteries [35]. Given that SDH is associated with a relatively good prognosis in patients with hematological malignancies, clinical awareness of neurological symptoms and signs in older patients, and the rapid use of neuroimaging, could improve diagnostic accuracy and thus the outcome of ICH. Although SAH represents only $5 \%$ of all strokes, it is responsible for $25 \%$ of all fatalities related to stroke in the general population [36].

In the current study, SAH affected only $21 \%$ patients with hematological malignancies but the mortality rate in the SAH group was $90 \%$. Advances have been made in surgical intervention for SAH [36], but none of the SAH patients in the current study received surgery. Surgical intervention showed a trend of improved 30-day outcome $(P=0.085)$ in the current study. Further research or surgical intervention is needed to improve the prognosis for SAH patients with hematological malignancies. Hemorrhage extending into the ventricles is associated with obstructive hydrocephalus and a relatively poor prognosis in ICH of general population [29,37]. Most patients with hematological malignancies who developed ICH had a poor prognosis. IVH is not an independent poor prognostic factor in patients with hematological malignancies.

Multivariate analysis using Cox's proportional hazard test revealed that $\mathrm{ICH}$ in patients with hematological malignancies was associated with three independent factors. These were prolonged prothrombin duration $(P=$ 0.008 ; OR 10.5 ; $95 \%$ CI 1.3 to 85.5$)$, subarachnoid hemorrhage $(P=0.021$; OR $10.9 ; 95 \%$ CI 1.3 to 89.9$)$, and multifocal cerebral hemorrhage $(P=0.026$; OR 4.7 ; $95 \%$ CI 1.6 to 14.0). Several studies have demonstrated that prolongation of prothrombin duration is related to fatal ICH outcome in patients with hematological malignancies [2-4]. The current study examined prolonged prothrombin duration as one of the independent prognostic factors for ICH in patients with hematological malignancies. Leukemic 
cells may express fibrinolysis and other proteolysis enzymes, which has been implicated in the pathogenesis of bleeding in some patients [38-40]. Chemotherapyrelated endothelial injury and reduction of coagulation factors also could play a role in the pathogenesis $[38,39]$. Coagulopathy in patients with hematological malignancies could play an important role in the pathogenesis of $\mathrm{ICH}$. Prolongation of prothrombin time could be ignored during the period of chemotherapy of patients with hematological malignancies; we suggest regular follow-up of prothrombin time and prompt correction in patients with hematological malignancies. This could potentially decrease the mortality of $\mathrm{ICH}$.

A total of 11 patients underwent craniotomy and hematoma evacuation. Surgical intervention showed a trend of improved 30-day outcome $(P=0.085)$ in $\mathrm{ICH}$ patients with hematological malignancies. Five of the seven survivors had long-term survival (more than 1 year) with minimal neurological sequelae. Although few patients underwent surgical intervention, we would advocate aggressive surgical treatment such as craniotomy and hematoma evacuation for those patients with non-refractory hematological malignancies. Recently, activated factor VII has been used successfully in patients with ICH [40-42]. A subsequent phase III clinical trial revealed that hemostatic therapy with rFVIIa reduced the growth of hematomas, but did not improve patient survival or functional outcome after intracerebral hemorrhage [43]. Further clinical trials should be conducted in $\mathrm{ICH}$ patients with hematological malignancies.

There were some limitations to this study. First, we tried to investigate all the adult patients with hematological malignancies. However, this study is a retrospective cohort in a single university hospital between 2001 and 2010 . Given the secular changes in the rapidly evolving field of hematology, patients may have received different chemotherapy protocols and supportive management. Second, thrombocytopenia (64\%), sepsis (47\%) and prolongation of prothrombin time $(21 \%)$ were the most common risk factors of $\mathrm{ICH}$. However, there was no patient autopsied for the definite cause of ICH. Furthermore, a prospective multicenter clinical study should be conducted to define the incidence of ICH in this population. We limited the definition of cases to patients with positive neuroimaging study to prevent confounding factors. Consequently, a few patients with refractory leukemia and lymphoma who did not consent to neuroimaging studies were excluded from this study.

\section{Conclusions}

$\mathrm{ICH}$ is more common in patients with AML than in patients with other types of hematological malignancy. ICH occurred in patients with lymphoma when there was CNS neoplastic involvement. Prognosis did not differ according to type of hematological malignancy. Prolonged prothrombin duration, $\mathrm{SAH}$, and multiplesite hemorrhage were all independent prognostic factors of $\mathrm{ICH}$ in patients with hematological malignancies. Neuroimaging studies of the location and type of $\mathrm{ICH}$ could assist with outcome prediction for patients with hematological malignancies.

\section{Acknowledgements}

This study was supported in part by the Taiwan National Scientific Council (grant NSC 99-2314-B-002-027-MY3). We thank the staff of the Eighth Core Laboratory, Department of Medical Research, National Taiwan University Hospital, for their technical support during the study.

\section{Author details}

'Department of Internal Medicine, National Taiwan University Hospital, Taipei, Taiwan. ${ }^{2}$ Department of Neurology, National Taiwan University Hospital, Taipei, Taiwan. ${ }^{3}$ Department of Internal Medicine, Division of Hematology and Oncology, Chi-Mei Hospital, Tainan, Taiwan. ${ }^{4}$ Tai-Cheng Stem Cell Therapy Center, National Taiwan University Hospital, Taipei, Taiwan. ${ }^{5}$ Department of Nursing, National Taiwan University Hospital, Taipei, Taiwan.

\section{Authors' contributions}

$\mathrm{C}-\mathrm{YC}, \mathrm{C}-\mathrm{HT}, \mathrm{H}-\mathrm{CW}$, and J-HL participated in the study design. S-YH, WT, MY, $\mathrm{P}-\mathrm{YC}, \mathrm{J}-\mathrm{LT}$ and $\mathrm{H}-\mathrm{FT}$ participated in data collection and analysis. C-YC, C-HT, $\mathrm{AC}$, and $\mathrm{H}-\mathrm{FT}$ participated in editing and proofreading. All authors read and approved the final manuscript.

\section{Competing interests}

The authors declare they have no competing interests.

Received: 3 February 2012 Accepted: 29 August 2012

Published: 29 August 2012

\section{References}

1. Rogers LR: Cerebrovascular complications in patients with cancer. Semin Neurol 2010, 30:311-319.

2. Chen CY, Tai CH, Tsay W, Chen PY, Tien HF: Prediction of fatal intracranial hemorrhage in patients with acute myeloid leukemia. Ann Oncol 2009, 20:1100-1104.

3. Dayyani F, Mougalian SS, Naqvi K, Shan J, Ravandi F, Cortes J, Weinberg J, Jabbour E, Faderl S, Wierda W, Thomas D, O'Brien S, Pierce S, Kantarjian H, Garcia-Manero G: Prediction model for mortality after intracranial hemorrhage in patients with leukemia. Am J Hematol 2011, 86:546-549.

4. Kim H, Lee JH, Choi SJ, Lee JH, Seol M, Lee YS, Kim WK, Lee JS, Lee KH: Risk score model for fatal intracranial hemorrhage in acute leukemia. Leukemia 2006, 20:770-776.

5. Yamauchi K, Umeda Y: Symptomatic intracranial haemorrhage in acute nonlymphoblastic leukaemia: analysis of $C T$ and autopsy findings. $J$ Neurol 1997, 244:94-100.

6. Rickles FR, Falanga A, Montesinos P, Sanz MA, Brenner B, Barbui T: Bleeding and thrombosis in acute leukemia: what does the future of therapy look like? Thromb Res 2007, 120(Suppl 2):S99-106.

7. Rogers LR: Management of stroke in cancer. Curr Oncol Rep 2008, 10:72-77.

8. Rogers LR: Cerebrovascular complications in cancer patients. Neurol Clin 2003, 21:167-192.

9. Glass J: Neurologic complications of lymphoma and leukemia. Semin Oncol 2006, 33:342-347.

10. Grisold W, Oberndorfer S, Struhal W: Stroke and cancer: a review. Acta Neurol Scand 2009, 119:1-16.

11. Rebulla P, Finazzi G, Marangoni F, Avvisati G, Gugliotta L, Tognoni G, Barbui T, Mandelli F, Sirchia G: The threshold for prophylactic platelet transfusions in adults with acute myeloid leukemia. Gruppo Italiano Malattie Ematologiche Maligne dell'Adulto. N Engl J Med 1997, 337:1870-1875. 
12. Blajchman MA, Slichter SJ, Heddle NM, Murphy MF: New strategies for the optimal use of platelet transfusions. Hematology Am Soc Hematol Educ Program 2008, 198-204.

13. Thomas X, Le QH: Central nervous system involvement in adult acute lymphoblastic leukemia. Hematology 2008, 13:293-302.

14. McMillan A: Central nervous system-directed preventative therapy in adults with lymphoma. Br J Haematol 2005, 131:13-21.

15. Shiber JR, Fines RE: Cerebral hemorrhage due to hyperleukocytosis. J Emerg Med 2011, 40:674-677.

16. Naunheim MR, Nahed BV, Walcott BP, Kahle KT, Soupir CP, Cahill DP, Borges LF: Diagnosis of acute lymphoblastic leukemia from intracerebral hemorrhage and blast crisis. A case report and review of the literature. Clin Neurol Neurosurg 2010, 112:575-577.

17. Wetzler M, Dodge RK, Mrózek K, Carroll AJ, Tantravahi R, Block AW, Pettenati MJ, Le Beau MM, Frankel SR, Stewart CC, Szatrowski TP, Schiffer CA, Larson RA, Bloomfield CD: Prospective karyotype analysis in adult acute lymphoblastic leukemia: the cancer and leukemia Group B experience. Blood 1999, 93:3983-3993.

18. de Labarthe A, Rousselot P, Huguet-Rigal F, Delabesse E, Witz F, Maury S, Réa D, Cayuela JM, Vekemans MC, Reman O, Buzyn A, Pigneux A, Escoffre M, Chalandon Y, Macintyre E, Lhéritier V, Vernant JP, Thomas X, Ifrah N, Dombret H, Group for Research on Adult Acute Lymphoblastic Leukemia (GRAALL): Imatinib combined with induction or consolidation chemotherapy in patients with de novo Philadelphia chromosomepositive acute lymphoblastic leukemia: results of the GRAAPH-2003 study. Blood 2007, 109:1408-13.

19. Cheng AL, Yeh KH, Uen WC, Hung RL, Liu MY, Wang CH: Systemic chemotherapy alone for patients with non-acquired immunodeficiency syndrome-related central nervous system lymphoma: a pilot study of the BOMES protocol. Cancer 1998, 82:1946-1951.

20. Anderson H, Scarffe JH, Lambert M, Smith DB, Chan CC, Chadwick G, McMahon A, Chang J, Crowther D, Swindell R: VAD chemotherapy-toxicity and efficacy-in patients with multiple myeloma and other lymphoid malignancies. Hematol Oncol 1987, 5:213-222.

21. Lazzarino M, Corso A, Barbarano L, Alessandrino EP, Cairoli R, Pinotti G, Ucci G, Uziel L, Rodeghiero F, Fava S, Ferrari D, Fiumanò M, Frigerio G, Isa L, Luraschi A, Montanara S, Morandi S, Perego D, Santagostino A, Savarè M, Vismara A, Morra E: DCEP (dexamethasone, cyclophosphamide, etoposide, and cisplatin) is an effective regimen for peripheral blood stem cell collection in multiple myeloma. Bone Marrow Transplant 2001 28:835-839.

22. Mehta J, Singhal S: Hyperviscosity syndrome in plasma cell dyscrasias. Semin Thromb Hemost 2003, 29:467-471.

23. Rubenstein J, Fischbein N, Aldape K, Burton E, Shuman M: Hemorrhage and VEGF expression in a case of primary CNS lymphoma. $J$ Neurooncol 2002, 58:53-56.

24. Kim IY, Jung S, Jung TY, Kang SS, Choi C: Primary central nervous system lymphoma presenting as an acute massive intracerebral hemorrhage: case report with immunohistochemical study. Surg Neurol 2008, 70:308-311.

25. Kimura N, Ishibashi M, Masuda T, Morishige M, Abe T, Fujiki M, Kashima K, Kumamoto T: Primary central nervous system lymphoma with cortical laminar hemorrhage. J Neurol Sci 2009, 287:281-284.

26. Anda T, Haraguchi W, Miyazato H, Tanaka S, Ishihara T, Aozasa K, Nakamichi l: Ruptured distal middle cerebral artery aneurysm filled with tumor cells in a patient with intravascular large B-cell lymphoma. J Neurosurg 2008, 109:492-496.

27. Ganguly S: Acute intracerebral hemorrhage in intravascular lymphoma: a serious infusion related adverse event of rituximab. Am J Clin Oncol 2007, 30:211-212.

28. Hunault-Berger $M$, Chevallier $P$, Delain $M$, Bulabois CE, Bologna $S$, Bernard M, Lafon I, Cornillon J, Maakaroun A, Tizon A, Padrazzi B, Ifrah N, Gruel Y, GOELAMS (Groupe Ouest-Est des Leucémies Aiguës et Maladies du Sang): Changes in antithrombin and fibrinogen levels during induction chemotherapy with L-asparaginase in adult patients with acute lymphoblastic leukemia or lymphoblastic lymphoma. Use of supportive coagulation therapy and clinical outcome: the CAPELAL study. Haematologica 2008, 93:1488-1494.

29. Alatoom A, Elsabrouty R, Willis J, Boils C, Sarode R, Hashim I, Wang HY: Fatal cerebral hemorrhage in a patient with CD19-positive IgM- producing aggressive plasma cell myeloma, hyperviscosity syndrome and cryoglobulinemia. Int J Clin Exp Pathol 2009, 2:498-507.

30. Reddy N, Karampelas I, Chanan-Khan A, Fenstermaker R, Padmanabhan S: Aggressive relapse of multiple myeloma with intracerebral extension and associated hemorrhage. Leuk Lymphoma 2007, 48:1228-1230.

31. Bleggi-Torres LF, Werner B, Gasparetto EL, de Medeiros BC, Pasquini R, de Medeiros CR: Intracranial hemorrhage following bone marrow transplantation: an autopsy study of 58 patients. Bone Marrow Transplant 2002, 29:29-32.

32. Elliott J, Smith M: The acute management of intracerebral hemorrhage: a clinical review. Anesth Analg 2010, 110:1419-1427.

33. Goldstein LB, Simel DL: Is this patient having a stroke? JAMA 2005, 293:2391-2402

34. Bleggi-Torres LF, de Medeiros BC, Werner B, Neto JZ, Loddo G, Pasquini R, de Medeiros CR: Neuropathological findings after bone marrow transplantation: an autopsy study of 180 cases. Bone Marrow Transplant 2000, 25:301-307.

35. Qureshi Al, Tuhrim S, Broderick JP, Batjer HH, Hondo H, Hanley DF: Spontaneous intracerebral hemorrhage. N Engl J Med 2001, 344:1450-1460.

36. Ferro JM, Canhao P, Peralta R: Update on subarachnoid haemorrhage. J Neurol 2008, 255:465-479.

37. Mayer SA, Rincon F: Treatment of intracerebral haemorrhage. Lancet Neurol 2005, 4:662-672.

38. Falanga A, Rickles FR: Management of thrombohemorrhagic syndromes (THS) in hematologic malignancies. Hematology Am Soc Hematol Educ Program 2007, 165-171.

39. Franchini M, Dario Di Minno MN, Coppola A: Disseminated intravascular coagulation in hematologic malignancies. Semin Thromb Hemost 2010, 36:388-403.

40. Siao D, Seetapah A, Ryman A, Guerin V, Mesli A, Maurette P: Optimal management of an aneurysmal subarachnoid hemorrhage in a patient with known factor XI deficiency: a case report. Clin Appl Thromb Hemost 2008, 14:108-111.

41. Adeoye O, Broderick JP: Advances in the management of intracerebral hemorrhage. Nat Rev Neurol 2010, 6:593-601.

42. Aguilar MI, Demaerschalk BM: Intracerebral hemorrhage. Semin Neurol 2007, 27:376-384.

43. Mayer SA, Brun NC, Begtrup K, Broderick J, Davis S, Diringer MN, Skolnick BE, Steiner T, FAST Trial Investigators: Efficacy and safety of recombinant activated factor VII for acute intracerebral hemorrhage. N Engl J Med 2008, 358:2127-2137.

Pre-publication history

The pre-publication history for this paper can be accessed here: http://www.biomedcentral.com/1741-7015/10/97/prepub

doi:10.1186/1741-7015-10-97

Cite this article as: Chen et al:: Intracranial hemorrhage in adult patients with hematological malignancies. BMC Medicine 2012 10:97.

\section{Submit your next manuscript to BioMed Central and take full advantage of:}

- Convenient online submission

- Thorough peer review

- No space constraints or color figure charges

- Immediate publication on acceptance

- Inclusion in PubMed, CAS, Scopus and Google Scholar

- Research which is freely available for redistribution

Submit your manuscript at www.biomedcentral.com/submit
C Biomed Central 